\title{
MICROPLASTICS AND MICROFIBERS IN THE SLUDGE OF A MUNICIPAL WASTEWATER TREATMENT PLANT
}

\author{
J. BAYO ${ }^{1}$, S. OLMOS ${ }^{1}$, J. LÓPEZ-CASTELLANOS ${ }^{2} \&$ A. ALCOLEA ${ }^{3}$ \\ ${ }^{1}$ Department of Chemical and Environmental Engineering, Technical University of Cartagena, Spain. \\ ${ }^{2}$ Aquambiente, Capitanes Ripoll, 8, Cartagena, Spain. \\ ${ }^{3}$ Support Service for Technological research, technical University of Cartagena, Spain.
}

\begin{abstract}
The presence of microplastics and synthetic microfibers in the environment is increasing, causing an accumulation in the food chain because their ingestion by different organisms in the ecological community. This paper deals with the importance of wastewater treatment plants (WWTPs) as a source of microplastics and microfibers from the sludge to the environment. These micropollutants have been monitored in an urban WWTP during 2015, after being separated from the sludge. Micropollutants were extracted by flotation, using a concentrated solution of sodium chloride and several stainless steel sieves. After an initial screening performed with a trinocular microscope, the samples were analyzed by Fourier transform infrared spectrometry and a differential scanning calorimeter, this last technique only for the identified subsamples. Significant matches with databases could be observed, identifying different compounds such as polypropylene, $\mathrm{Nylon}^{\odot}$, transparent thermoplastic polyamides, norbornene, and ethyl acrylate, among others. These microplastics and microfibers could be transported with organic matter on fertilizers, being used as compost in the field crops of Campo de Cartagena.

Keywords: microfibers, microplastics, sludge, wastewater treatment plant.
\end{abstract}

\section{INTRODUCTION}

The presence of plastics in the environment, since mass production began in the 40s, has been an issue that has aroused great public and scientific interest. Although until recently, and even today, the source of the problem was focused in litter originated from big plastics, since the beginning of this XXI century, the plastic fragments, fibers and granules, collectively known as microplastics, are considered as a new type of contaminant by itself [1]. Because of their small size, these microplastics are taken for food by phytoplankton, entering the food chain that ultimately affect humans. Besides these, microplastics and microfibers can be carriers, by an adsorption mechanism, of hazardous compounds such as heavy metals, polychlorinated biphenyls (PCBs), persistent organic pollutants (POPs), etc. Microplastics can be divided into two main groups: primary microplastics directly manufactured with this size $(<5 \mathrm{~mm})$ such as scrubbers in personal care products (PCPs) [2], as well as manufactured pellets used in feedstock and plastic production [3], and secondary microplastics, or small fragments from the breakup and breakdown of larger waste plastics [4].

Nowadays, it is believed that more than 250 species including fishes, sea birds, turtles and marine mammals are affected by ingestion of these micropollutants [5]. This ingestion causes adverse health effects because microplastics are composed of a wide range of polymers derived from multiple sources, which makes their intake may be the introduction of toxins 
into the base of the food chain. Thus, problems in swallowing microplastics would focus both physical or block damage these micropollutants can have on the digestive tract of animals, and leaching of chemicals that make plastic components with contaminants, besides those that could be adsorbed in the meantime.

The main objective of this study was the analysis and characterization of microplastics and microfibers in the sludge of an urban wastewater treatment plant (WWTP), likely to reach the environment and different ecosystem types.

The lack of standardized methods of sampling and analysis has complicated the comparison among the results of a few studies, making it necessary the development of a sampling and extraction technique.

\section{MATERIALS AND METHODS}

\subsection{Sample collection}

The study was conducted with sludge samples from the centrifuge, after the anaerobic digestion process (sludge $\mathrm{C}$ ), and the rejection of the primary clarifier (sludge P), obtained from the WWTP 'Cabezo Beaza' of Cartagena, a Mediterranean city located in the Southeast of Spain. This plant receives wastewater from both urban and industrial activities, and consists of a conventional activated sludge process with a primary treatment and two parallel activated sludge bioreactors, serving about 210,000 equivalent inhabitants $\left(35,000 \mathrm{~m}^{3} \mathrm{~d}^{-1}\right)$ [6]. All samples were collected in glass containers to avoid additional contamination, and kept refrigerated at $4^{\circ} \mathrm{C}$ on arrival to the laboratory.

\subsection{Extraction and identification of microplastics in sludge}

Microplastics and microfibers were extracted from sludge through the density separation method of Vianello et al. [7], slightly modified. It is based on the ability of a concentrate sodium chloride solution $\left[\mathrm{NaCl} ; 120 \mathrm{gl}^{-1}\right.$ ) to remove these micropollutants from sludge, resulting in a supernatant with floating particles. The concentrated solution was prepared in an Erlenmeyer flask of 1,000 ml capacity.

An aliquot of $50 \mathrm{~g}$ (ww) was weighed from each sample, in duplicate, with the aid of a glass crucible. Samples were shaken with the solution for $60 \mathrm{~min}$ in a 1-1 glass beaker to a final volume of $500 \mathrm{ml}$, by using an orbital shaker at $200 \mathrm{rpm}$.

After 1 hour stirring, the mixture was allowed to settle for another hour, and the supernatant was subjected to wet sieving through a No. 200 mesh (Sigma-Aldrich, Saint Louis, MO, USA) for sludge C, and through a No. 20 mesh and No. 200 mesh for sludge P, to obtain different sorted particles, i.e., $0.850 \mathrm{~mm}$ and $0.075 \mathrm{~mm}$, respectively, as this last sludge $\mathrm{P}$ had macroscopic particles that could hide the smaller ones. This procedure was repeated twice, and the extracted fractions were dried at $60^{\circ} \mathrm{C}$ for 1 hour, and stored in glass vessels.

After a first screening through a trinocular microscope, we could observe that microparticles (mainly microfibers) were impregnated with organic matter to form compact and rigid structures. In order to remove it, extracted samples with general method were crushed in an agate mortar and diluted in $10 \mathrm{ml}$ isopropyl alcohol for $48 \mathrm{~h}$ at $60^{\circ} \mathrm{C}$. After extraction, the resulting mixture was centrifuged at 5,000 rpm for $2 \mathrm{~min}$ and dried in lab stove for $1 \mathrm{~h}$. 


\subsection{Microscopic analyses}

Microscopic analyses were carried out with an Olympus SZ61 trinocular microscope (Edmund Optics Spain, Canary Islands), providing a superior image quality with a $10^{\circ}$ convergence angle at a working distance of $110 \mathrm{~mm}$, magnification range from $6.7 \times$ to $45 \times$ and LED lighting. This trinocular microscope was coupled with an Olympus Altra 20 high resolution digital camera, with a maximum resolution of 1,596 $\times 1,196$ pixels, 10 bits per color channel, 7.5 frames per second at full resolution, and $0.1 \mathrm{~ms}$ to $1 \mathrm{~s}$ exposure time.

\subsection{FTIR}

The infrared spectra were acquired with a Thermo Nicolet 5,700 Fourier transformed infrared (FTIR) spectrometer (Thermo Nicolet Analytical Instruments, Madison, WI, USA), provided with a deuterated triglycine sulfate (DTGS) detector and $\mathrm{KBr}$ detector. The spectra collected were an average of 20 scans with a resolution of $16 \mathrm{~cm}^{-1}$ in the range of 4,000-400 $\mathrm{cm}^{-1}$. Spectra were controlled and evaluated by the OMNIC software package, by means of a reference spectra database, where peak maxima were manually determined after examination of absorbance values.

\section{$2.5 \mathrm{DSC}$}

A differential scanning calorimeter (DSC822e, Mettler Toledo, Barcelona, Spain) was used to investigate the heat flow of samples while heated according to the following pattern: steady temperature ramp from $25^{\circ} \mathrm{C}$ to $300^{\circ} \mathrm{C}\left(20^{\circ} \mathrm{C} \cdot \mathrm{min}^{-1}\right)$, isothermal period $300^{\circ} \mathrm{C}(2 \mathrm{~min})$, steady temperature ramp from $-50^{\circ} \mathrm{C}$ to $400^{\circ} \mathrm{C}\left(20^{\circ} \mathrm{C} \cdot \mathrm{min}^{-1}\right)$, isothermal period at $400^{\circ} \mathrm{C}(2 \mathrm{~min})$. Assays were performed in inert atmosphere, with a constant flow of $50 \mathrm{ml} \cdot \mathrm{min}^{-1}$.

\section{RESULTS AND DISCUSSION}

\subsection{General considerations}

The macroscopic visual observation of samples or initial screening showed that they contained a lot of organic matter, as depicted in Fig. 1, so it was necessary to use a binocular microscope for an appropriate treatment. After that, the samples were classified into subsamples, as presented in Table 1. All samples were collected during the months of February, March and April 2015.

Subsequently, subsamples were characterized by FTIR spectroscopy and DSC since, although there is very little information about the retention efficiency of microplastics and microfibers in WWTP, differents researchers have previously used these analytical techniques for their identification $[8,9]$.

\subsection{FTIR applied to sludge $\mathrm{C}$ subsamples}

As previously indicated, spectra were controlled and evaluated by the OMNIC software, by means of a reference spectra database, and interpreted according to Pretsch et al. [10]. The main matching compounds are presented in Table 2. Zein, a protein with a great potential for use in the bioplastics industry [11], appeared to be the main component of subsample_1.1C 
Table 1: Samples and subsamples.

\begin{tabular}{|c|c|c|}
\hline & Samples & Subsamples \\
\hline \multirow[t]{14}{*}{ Sludge C } & \multirow[t]{8}{*}{ Sample 1C } & Subsample_1.1C \\
\hline & & Subsample_1.2C \\
\hline & & Subsample_1.3C \\
\hline & & Subsample_1.4C \\
\hline & & Subsample_1.5C \\
\hline & & Subsample_1.6C \\
\hline & & Subsample_1.7C \\
\hline & & Subsample_1.8C \\
\hline & \multirow[t]{2}{*}{ Sample 2C } & Subsample_2.1C \\
\hline & & Subsample_2.2C \\
\hline & \multirow[t]{4}{*}{ Sample 3C } & Subsample_3.1C \\
\hline & & Subsample_3.2C \\
\hline & & Subsample_3.3C \\
\hline & & Subsample_3.4C \\
\hline \multirow[t]{7}{*}{ Sludge P } & \multirow[t]{4}{*}{ Sample 1P } & Subsample_1.1P \\
\hline & & Subsample_1.2P \\
\hline & & Subsample_1.3P \\
\hline & & Subsample_1.4P \\
\hline & \multirow[t]{3}{*}{ Sample 2P } & Subsample_2.1P \\
\hline & & Subsample_2.2P \\
\hline & & Subsample_2.3P \\
\hline
\end{tabular}

and subsample_1.6C, with a concordance of $83.45 \%$ and $69.08 \%$ with the reference spectra database, respectively. Bioplastics comprise of a whole family of materials, either based on biological stems (corn, sugarcane, etc.) or biodegradable, or featuring both properties [12]. Zein-based polymers are commonly used as a material for the formation of films, coatings, microspheres and microcapsules due to their excellent strength properties. Zein has a high fragility so it is necessary to add plasticizers to delay the formation of coating cracks [13].

Ethyl acrylate $\left(\mathrm{CH}_{2}=\mathrm{CH}-\mathrm{COO}-\mathrm{CH}_{2}-\mathrm{CH}_{3}\right)$ appeared to be the main component in subsample_1.2C and subsample_3.2C. It is an important monomer used for manufacturing various types of polymers and copolymers, including resins, plastics, rubber and dental material. As a monomer, ethyl acrylate is toxic, and may cause irritation and burn of eyes and skin [14]. Maleki et al. [15] reported the use of ethyl acrylate grafted chitosan as a biopolymer for $\mathrm{Pb}(\mathrm{II}), \mathrm{Cd}(\mathrm{II})$ and $\mathrm{Zn}(\mathrm{II})$ adsorption in wastewaters. So, it provides a feasible pathway to transfer attached heavy metals as well as additive chemicals into the food chain [16].

Grilamid ${ }^{\circledR}$ TR 55 is a transparent thermoplastic polyamide, suitable for industrial production in the fields of optics, electronics, automotive, packaging, sanitary components (replacement of brass) and domestic appliances, among others. Lenz et al. [17] have reported its use in nylon-jacketed cable products, that avoids the attack of insects. As a nylon resin, it is used as an eyeglass frame material and to make sweaters. Habib et al. [18] also found 

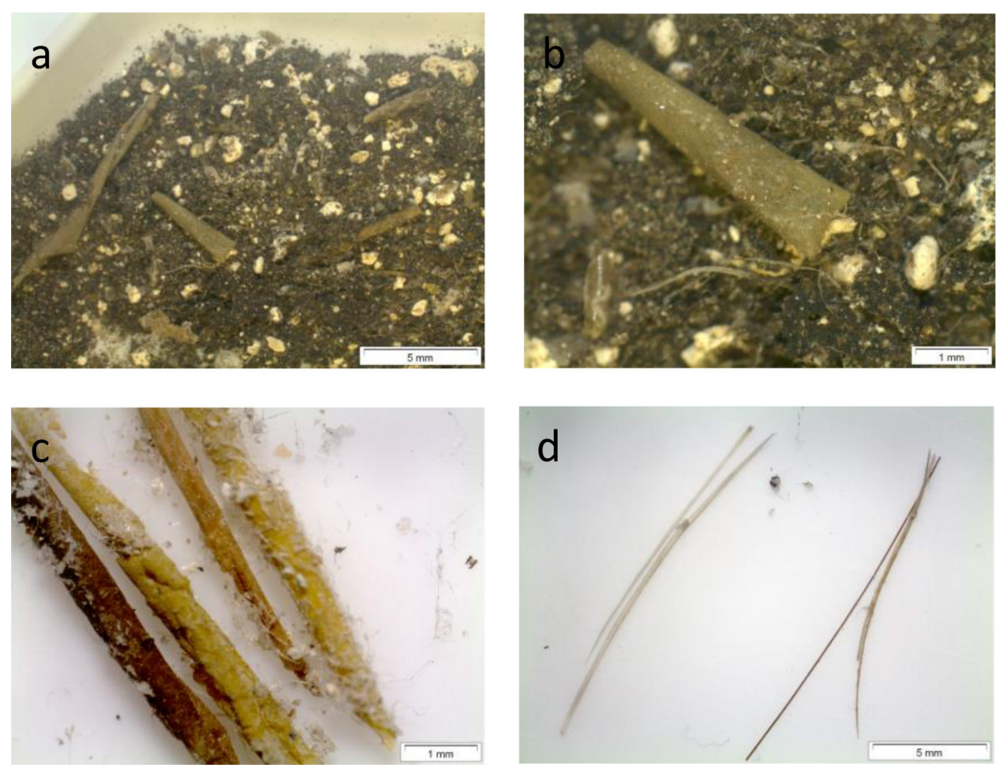

Figure 1: Binocular microscope images from sludge C (subsample_1.1C) (a) 6x magnification, and (b) 20× magnification; and sludge $\mathrm{P}$ (subsample_1.1P) (c) $20 \times$ magnification, and (d) $6 \times$ magnification.

synthetic fibers in sludge from a WWTF, whose origin would be the gray water from laundry; during the spinning process, they would be detached from the tissue by mechanical action and incorporated into the wastewater. Due to its low biodegradability in the biological process taking place in the WWTF, these fibers would be incorporated into the sludge or the treated effluent.

Subsample_3.3C displayed a soapy and whitish appearance, turning out to be, with a $85 \%$ match, calcium stearate. This is a normally used compound for the manufacturing of cosmetics, soaps, and fabric softeners, among others, hence its appearance in sludges of WWTP.

The main component for subsample_1.8C was a norbornene derivative, a flame retardant thermoplastic elastomer addded to polymeric materials in order to prevent fire. Dec 602 $\left(\mathrm{C}_{14} \mathrm{H}_{4} \mathrm{Cl}{ }_{12} \mathrm{O}\right)$ Dec $603\left(\mathrm{C}_{17} \mathrm{H}_{8} \mathrm{Cl}_{12}\right)$ Dec $604\left(\mathrm{C}_{13} \mathrm{H}_{4} \mathrm{Br}_{4} \mathrm{Cl}_{6}\right)$ and Declorane Plus $\left(\mathrm{C}_{18} \mathrm{H}_{12} \mathrm{Cl}_{12}\right)$ were introduced as substitutes for Mirex $\left(\mathrm{C}_{10} \mathrm{Cl}_{12}\right)$, an organochlorine pesticide that was also used as a flame retardant in the 1960s but was banned due to their toxicological properties in the 1970s. Currently, these pollutants are being detected in the environment, both in sediments, air and water, as well as fish, eggs, blood and hair [18]. In Spain, Barón et al. [19, 20] have reported the presence of these retardants in the Ebro river, as well as the sludges of six WWTP close to that river. Despite their constant appearance, knowledge about the presence of these pollutants, its fate and behavior is still very limited.

The highest matching score was for polyolefins. These include related plastics polyethylene (PE), both low and high density (LDPE and HDPE, respectively) and polypropylene (PP). Due to its switching behavior, these compounds could be secondary microplastics, originated from the breakdown of larger plastic items, such as plastic bags, films, bottle caps and rings of six-packs of soda, and synthetic textile [21,22], as well as primary source microplastics included in PCPs such as facials, exfoliating creams and toothpastes [23]. 
Table 2: List of main components matching the reference spectra database for subsamples of sludge $\mathrm{C}$.

\begin{tabular}{|c|c|c|}
\hline Subsample & Match $(\%)$ & Compound name \\
\hline $1.1 \mathrm{C}$ & 83.45 & Zein, purified \\
\hline $1.2 \mathrm{C}$ & 70.08 & Ethyl acrylate copolymer \\
\hline $1.3 \mathrm{C}$ & 71.04 & Grilamid $^{\circledR}$ TR 55 \\
\hline $1.4 \mathrm{C}$ & 75.97 & Phosphate Amorphe Calcium Carbonate \\
\hline $1.5 \mathrm{C}$ & 70.56 & Grilamid $^{\circledR}$ TR 55 \\
\hline $1.6 \mathrm{C}$ & 69.08 & Zein, purified \\
\hline $1.7 \mathrm{C}$ & 90.96 & ARC 1,001 (cast) \\
\hline $1.8 \mathrm{C}$ & 89.55 & Poly(ethylene:propylene:ethylidene norbornene) \\
\hline $2.1 \mathrm{C}$ & 46.80 & Polyamide resin $(n=39$ p/400F) \\
\hline $2.2 \mathrm{C}$ & 96.94 & Poly(1-decene), isotactic \\
\hline $3.1 \mathrm{C}$ & 68.02 & Ethyl cellulose ( $48 \%$ ethoxyl, $n=10$ ) \\
\hline $3.2 \mathrm{C}$ & 60.66 & Poly(ethylene:ethyl acrylate) \\
\hline $3.3 \mathrm{C}$ & 85.28 & Calcium stearate \\
\hline $3.4 \mathrm{C}$ & 97.77 & Poly(1-decene), isotactic \\
\hline
\end{tabular}

The FTIR analysis also allowed us to measure the degree of oxidation by using the relative oxidation percentage, assumed as the peak area at $1650-1850 \mathrm{~cm}^{-1}$ divided by the carbonyl peak area $\left(1,720 \mathrm{~cm}^{-1}\right)$. This percentage corresponds to the amount of polyolefin undergoing thermo-oxidation, photo-oxidation or radio-oxidation at any time of its lifecycle [24], that is, manufacture, distribution or use, resulting in structural effects such as chain breakage or crosslinking. A number of factors are responsible for the deterioration of polymer properties, such as: oxidative and thermal degradation, UV irradiation, climate factors, mechanical stresses, etc. [25].

Subsample_2.2C and subsample_3.4C proved to be in a $20 \%$ degradation process, with a relative mass and resistance losses, affecting in their mechanical properties.

\subsection{FTIR applied to sludge P subsamples}

For the P-type mud, as shown in Table 3 displays the main constituents of sludge $\mathrm{P}$ subsamples, with the same compounds as explained before, except for silk, a natural protein fiber used in the textile industry, and because its lability, this fiber can only be found in the sludge $\mathrm{P}$, before sludge anaerobic digestion and centrifugation.

\subsection{DSC}

DSC was used as a rapid and cost effective instrumental method for studying polymers degradation mechanisms [25]. This technique has always been used to develop thermal property data for single component polymers [26]. In our styudy, it was applied, with the previously described pattern, on subsample_1.1C, subsample_1.2C, and subsample_1.8C, as depicted in Table 4, because of insufficient sample amount for other subsamples. 
Table 3: List of main components matching the reference spectra database for subsamples of sludge $\mathrm{P}$.

\begin{tabular}{lcl}
\hline Subsample & Match $(\%)$ & Compound name \\
\hline $1.1 \mathrm{P}$ & 64.39 & Grilamid® TR 55 \\
$1.2 \mathrm{P}$ & 69.04 & Silk II \\
$1.3 \mathrm{P}$ & 55.37 & Poly(octadecyl acrylate) \\
$1.4 \mathrm{P}$ & 80.97 & Octadenoic acid \\
$2.1 \mathrm{P}$ & 74.19 & Poly(ethylene:ethyl acrylate) \\
$2.2 \mathrm{P}$ & 90.37 & Poly(ethylene:ethyl acrylate) \\
$2.3 \mathrm{P}$ & 73.72 & Cellulose \\
\hline
\end{tabular}

Table 4: Differential scanning calorimeter procedure.

\begin{tabular}{llccc}
\hline & & \multicolumn{3}{c}{ Weight (mg) } \\
\cline { 3 - 5 } Subsample & Heating & Melting pot & $\begin{array}{c}\text { Melting pot \& } \\
\text { Subsample }\end{array}$ & subsample \\
\hline Subsample_1.1C & 1st heating & 33.147 & 33.250 & 0.103 \\
& 2nd heating & 33.147 & 33.180 & 0.033 \\
Subsample_1.2C & 1st heating & 33.144 & 35.643 & 2.499 \\
& 2nd heating & 33.144 & 35.370 & 2.226 \\
Submuestra_1.8C & 1st heating & 32.797 & 33.105 & 0.310 \\
& 2nd heating & 32.797 & 32.997 & 0.200 \\
\hline
\end{tabular}

As FTIR showed the presence of water stretching vibrations of $\mathrm{OH}$ bond in the range of $3,500-3,100 \mathrm{~cm}^{-1}$, the characterization by DSC caused a mass loss of $68 \%, 11 \%$, and $36 \%$ for subsample_1.1C, subsample_1.2C, and subsam-ple_1.8C, respectively.

Figure 2 shows the DSC analysis for subsample_1.2C. The endothermic peak corresponding to $161.93^{\circ} \mathrm{C}$ observed with this material, quite approaches the melting point of polypropylene $\left(165^{\circ} \mathrm{C}\right)$ with a fusion enthalpy of $\Delta \mathrm{H}_{\mathrm{f}}=0.47 \mathrm{~J} / \mathrm{g}$.

\section{CONCLUSIONS}

The study is presented as a first screeening on microfibers and microplastics in the sludges of an urban WWTP. The results clearly indicate their presence, both in the sludge from the primary clarifier (primary treatment) and after the anaerobic digestion and centrifugation, the last step before disposal and use as an amendment in agriculture. The results of this research suggest that sludges from WWTP can be a source of these micropollutants towards soil, freshwater and marine environments. However, the evaluation of the role of sewage plants in the total microplastic and microfiber load to the environment needs further investigations.

An important variety and amount of different types of microplastics and microfibers was detected in this investigation, highlighting the presence of bioplastic residues, ethyl acrylate, 


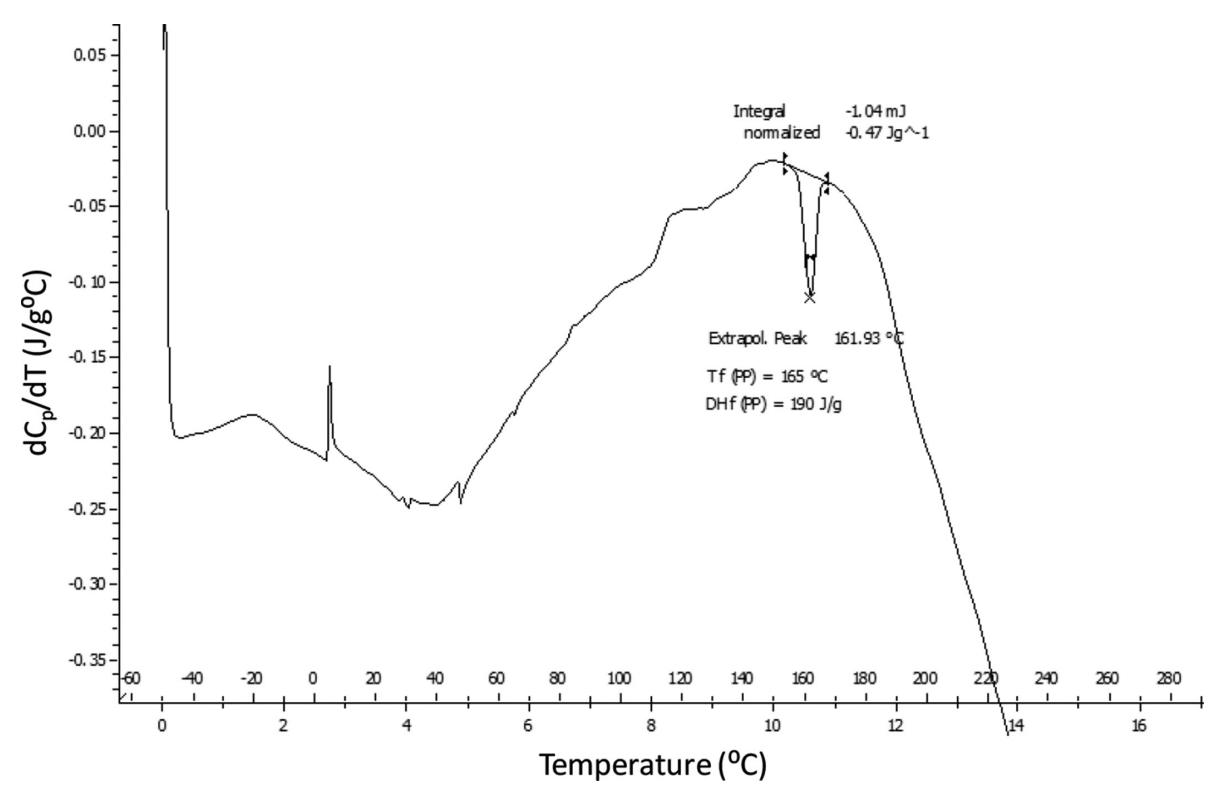

Figure 2: $\mathrm{dC}_{\mathrm{p}} / \mathrm{dT}$ versus $\mathrm{T}$ for subsample_1.2C.

different polyamides such as Grilamid ${ }^{\circledR}$ TR 55, polyolefins, and a norbornene derivative, a flame retardant thermoplastic added to different polumeric materials, among others. All of them were confirmed by FTIR analysis. The presence of these micropollutants also threat to biota, as their small size makes them available to a wide range of aquatic and soil organisms. Besides, these synthetic microcomponents can also result in a toxic response due to inherent monomers leaching from their composition, as well as common plasticisers that may be incorporated into plastics during manufacture.

In another toxicity level, microplastics and microfibers have a large surface area to volume ratio; for that reason, they can adsorb different pollutants including heavy metals, POPs and PCBs, that will be monitored in a following research.

Although there is no specific policy designed to prevent environmental pollution with microplastics and microfibers in Europe, at the moment, some countries like The Netherlands, Austria, Belgium and Sweden are being pioneers. They have come together to apply the prohibition on the use of microplastics, indicating that could get alliances with producers to find substitutes for these items, so protecting the environment for the so-called 'microplastic soup'. In special, the cosmetics industry is under fire worldwide because of its use in PCPs. In this sense, some commercial brands, like Colgate-Palmolive have kept their promise and have eliminated this micropollutants from their toothpastes. Furthermore, 69 NGO's in 33 countries are supporting the 'Beat the Microbead' campaign, calling to ban the use of tiny plastic beads in cosmetics and PCPs [27].

\section{REFERENCES}

[1] Ryan, P.G., Moore, C.J., van Franeker, J.A. \& Moloney, C.L., Monitoring the abundance of plastic debris in the marine environment. Philosophical Transactions of the Royal Society B: Biological Sciences, 364, pp. 1999-2012, 2009.

http://dx.doi.org/10.1098/rstb.2008.0207 
[2] Barnes, D.K.A., Galgani, F., Thompson, R.C. \& Barlaz, M., Accumulation and fragmentation of plastic debris in global environments. Philosophical Transactions of the Royal Society B: Biological Sciences, 364, pp. 1985-1998, 2009. http://dx.doi.org/10.1098/rstb.2008.0205

[3] Eerkes-Medrano, D., Thompson, R.C. \& Aldridge, D.C., Microplastics in freshwater systems: a review of the emerging threats, identification of knowledge gaps and prioritisation of research needs. Water Research, 75, 93-82, 2015. http://dx.doi.org/10.1016/j.watres.2015.02.012

[4] Derraik, J., The pollution of the marine environment by plastic debris: a review. Marine Pollution Bulletin, 44, pp. 842-852, 2002. http://dx.doi.org/10.1016/S0025-326X(02)00220-5

[5] Ugolini, A., Ungherese, G., Ciofini, M. \& Lapuccio, A., Microplastic debris in sandhoppers. Estuarine Coastal and Shelf Science, 129, pp. 19-22, 2013. http://dx.doi.org/10.1016/j.ecss.2013.05.026

[6] Bayo, J., Angosto, J.M. \& Gómez-López, M.D., Ecotoxicological screening of reclaimed disinfected wastewater by Vibrio fischeri bioassay after a chlorination-dechlorination process. Journal of Hazardous Materials, 172, pp. 166-171, 2009. http://dx.doi.org/10.1016/j.jhazmat.2009.06.157

[7] Vianello, A., Boldrin, A., Guerriero, P., Moschino, V., Rella, R., Sturaro, A. \& Da Ros, L., Microplastic particles in sediments of Lagoon of Venice, Italy: first observations on occurrence, spatial patterns and identification. Estuarine Coastal and Shelf Science, 130, pp. 54-61, 2013. http://dx.doi.org/10.1016/j.ecss.2013.03.022

[8] Magnusson, K. \& Norén, F., Screening of microplastic particles in and down-stream a wastewater treatment plant, IVL Swedish EnviromentalEnvironmental Research Institute, 2014.

[9] Talvitie, J. \&Heinonen, M., Preliminary study on synthetic microfibers and particles at a municipal waste water treatment plant, HELCOM, BASE project 2012-2014, 2014.

[10] Pretsch, E., Bühlmann, P. \& Affolder, C., Structure Determination of Organic Compounds. Tables of Spectral Data, 3rd edn., Springer: Berlin, 2000.

http://dx.doi.org/10.1007/978-3-662-04201-4

[11] Sessa, D.J., Cheng, H.N., Kim, S., Selling, G.W. \& Biswas, A., Zein-based polymers formed by modifications with isocyanates. Industrial Crops and Products, 43, pp. 106113, 2013. http://dx.doi.org/10.1016/j.indcrop.2012.06.034

[12] Siracusa, V., Rocculi, P., Romani, S. \& Rosa, M.D., Biodegradable polymers for food packaging: a review. Trends in Food Science \& Technology, 19, pp. 634-643, 2008. http://dx.doi.org/10.1016/j.tifs.2008.07.003

[13] Yong, Z., Lili, C., Xiaoxia, C., Heng, Z. \& Nianqiu, S., Zein-based films and their usage for controlled delivery: origin, classes and current landscape. Journal of Controlled Release, 206, pp. 206-219, 2015.

http://dx.doi.org/10.1016/j.jconrel.2015.03.030

[14] Sun, Y., Zhang, Q., Hu, J., Chen, J. \& Wang, W., Theoretical study for OH radical-initiated atmospheric oxidation of ethyl acrylate. Chemosphere, 119, pp. 626-633, 2015. http://dx.doi.org/10.1016/j.chemosphere.2014.07.056

[15] Maleki, A., Pajootan, E. \& Hayati, B., Ethyl acrylate grafted chitosan for heavy metal removal from wastewater: equilibrium, kinetic and thermodynamic studies. Journal of the Taiwan Institute of Chemical Engineers, 51, pp. 127-134, 2015.

http://dx.doi.org/10.1016/j.jtice.2015.01.004 
[16] Browne, M.A., Niven, S.J., Gallowy, T.S., Rowland, S.J. \& Thompson, R.C., Microplastic moves pollutants and additives to worms, reducing functions linked to health and biodiversity. Current Biology, 23, pp. 2388-2392, 2013. http://dx.doi.org/10.1016/j.cub.2013.10.012

[17] Lenz, M., Creffield, J.W., Evans, T.A., Kard, B., Vongkaluang, C., Sornnuwat, Y., Lee, C.Y., Yoshimura, T. \& Tsunoda, K., Resistance of polyamide and polyethylene cable sheathings to termites in Australia, Thailand, USA, Malaysia and Japan: a comparison of four field assessment methods. International Biodeterioration \& Biodegradation, 66, pp. 53-62, 2012.

http://dx.doi.org/10.1016/j.ibiod.2011.11.001

[18] Shen, L., Reiner, E.J., Macpherson, A.K. \& Kolic, T.M., Identification and screening analysis of halogenated norbornene flame retardants in the laurentian great lakes: dechloranes 602, 603 and 604. Environmental Science \& Technology, 44, pp. 760-766, 2010 .

http://dx.doi.org/10.1021/es902482b

[19] Barón, E., Eljarrat, E. \& Barceló, D., Analytical method for the determination of halogenated norbornene flame retardants in environmental and biota matrices by gas chromatography coupled to tandem mass spectrometry. Journal of Chromatography A, 1248, pp. 154-160, 2012.

http://dx.doi.org/10.1016/j.chroma.2012.05.079

[20] Barón, E., Bosch, C., Máñez, M., Andreu, A., Sergio, F., Hiraldo, F., Eljarrat, E. \& Barceló, D., Temporal trends in classical and alternative flame retardants in birds eggs from doñana natural space and surrounding areas (south-western Spain) between 1999 and 2013. Chemosphere, 138, pp. 316-323, 2015.

http://dx.doi.org/10.1016/j.chemosphere.2015.06.013

[21] Andrady, A., Microplastics in the marine environment. Marine Pollution Bulletin, 62, pp. 1596-1605, 2011. http://dx.doi.org/10.1016/j.marpolbul.2011.05.030

[22] Cole, M., Lindeque, P., Halsband, C. \& Galloway, T., Microplastics as contaminants in the marine environment: a review. Marine Pollution Bulletin, 62, pp. 2588-2597, 2011. http://dx.doi.org/10.1016/j.marpolbul.2011.09.025

[23] Fendall, L. \& Sewell, M., Contributing to marine pollution by washing your face: microplastics in facial cleansers. Marine Pollution Bulletin, 58, pp. 1225-1228, 2009. http://dx.doi.org/10.1016/j.marpolbul.2009.04.025

[24] Pospísil, J. \& Nespurek, S., Chain-breaking stabilizers in polymers: the current status. Polymer Degradation and Stability, 49, pp. 99-110, 1995. http://dx.doi.org/10.1016/0141-3910(95)00043-L

[25] Ilie, S. \& Senetscu, R., Polymeric materials review on oxidation, stabilization and evaluation using CL and DSC methods. TN Technical Note, avaliableavailable at cdsweb. cern.ch/record/1201650/files/Ilie_TE_Technical_Notes.pdf

[26] Tripathi, A.K., Tsavalas, J.G. \& Sundberg, D.C., Quantitative measurements of the extent of phase separation during and after polymerization in polymer composites using DSC. Thermochimica Acta, 568, pp. 20-30, 2013. http://dx.doi.org/10.1016/j.tca.2013.06.013

[27] Cosmetics industry in the USA and EU speak out about ban on microplastics, avaliable at www.plasticsopufoundation.org 